\title{
Study on durability of natural fibre concrete composites using mechanical strength and microstructural properties
}

\author{
M SIVARAJA*, KANDASAMY ${ }^{\dagger}$, N VELMANI $^{\dagger \dagger}$ and M SUDHAKARAN PILLAI ${ }^{\#}$ \\ Department of Civil Engineering, ${ }^{\dagger}$ Department of Chemical Engineering, Kongu Engineering College, \\ Perundurai, Erode 638 052, India \\ ${ }^{\dagger}$ Anna University - Trichy, Ariyalur Campus, Tiruchirapalli 621 713, India \\ ${ }^{\#}$ Central Institute of Coir Technology, Coir Board, Bangalore 560 058, India
}

MS received 24 June 2009; revised 19 October 2009

\begin{abstract}
Investigations to overcome the brittle response and limiting post-yield energy absorption of concrete led to the development of fibre reinforced concrete using discrete fibres within the concrete mass. Out of the commonly used fibres, easily available low cost natural fibres are renewable source materials. Though these fibres are ecologically advantageous, they have some limitations such as lower durability and lesser strength. But recent research provides several treatment processes to enhance the durability of natural fibres. In this paper, the durability of natural fibres such as coconut coir and sugarcane bagasse has been reported by conducting an experimental investigation. This investigation includes two parts. The first part focuses on the determination of mechanical strength properties such as compressive, tensile, modulus of rupture and flexural properties of natural fibre reinforced concrete specimens once every 3 months for a period for 2 years under alternate wetting and drying conditions. Gain or loss in strength of composite concrete at 9 intervals were computed and are reported here. The second part covers the microstructural properties of fresh natural fibres in as received condition and natural fibres reacted with concrete under accelerated curing conditions for two years. SEM and EDAC test results are discussed.
\end{abstract}

Keywords. Natural fibres; concrete composite; mechanical strength; SEM analysis.

\section{Introduction}

Natural fibres are prospective reinforcing materials and their use until now has been more traditional than technical. They have long served many useful purposes but the application of materials technology for the utilization of natural fibres as the reinforcement in concrete has only taken place in comparatively recent years. The distinctive properties of natural fibre reinforced concretes are improved tensile and bending strength, greater ductility, greater resistance to cracking and hence improved impact strength and toughness. Besides its ability to sustain loads, natural fibre reinforced concrete is also required to be durable. Durability relates to its resistance to deterioration resulting from external causes as well as internal causes (Aziz et al 1984).

Earlier, mechanical characterization and impact behaviour of concrete reinforced with natural fibres were studied (Al-Oraimi and Seibi 1995). Here an experimental study was done using glass and palm tree fibres on high strength concrete. Mechanical strength properties such as compressive, split tensile, flexural strengths and post cracking

\footnotetext{
*Author for correspondence (m.shivaraj2006@gmail.com)
}

toughness were studied. It was concluded that natural fibres are comparable with glass fibres. A finite element analysis was also done using ANSYS software. Both the analytical and experimental results were compared and found acceptable. Comparison between theoretical and experimental investigations on the compressive strength and elastic modulus of coir and sisal fibre reinforced concretes for various volume fractions was also carried out (Ramakrishna and Sundararajan 2002). It was observed that both the experimental and analytical values of elastic modulus had shown $15 \%$ discrepancy, which can be regarded as comparatively small.

Rheological properties of coir fibre reinforced cement mortar in terms of flow value, cohesion and angle of internal friction were determined for three different mix ratios and four different aspect ratios and fibre contents (Ramakrishna and Sundararajan 2002). Based on the rheological properties of fresh mortar, it was recommended to use shorter fibres with low fibre-content for achieving workability and higher fibre content for better cohesiveness in wet state. Previously sugarcane bagasse fibre reinforced cement composites were studied (Bilba et al 2003). Various bagasse fibre-cement composites were prepared and their influence on various parameters on the setting of the composite materials were studied. Botanical components, 
thermal and chemical treatment of bagasse fibres were also studied.

The natural fibre composites may undergo a reduction in strength and toughness as a result of weakening of fibres by the combination of alkali attack and mineralization through the migration of hydrogen products to lumens and spaces. Earlier researchers (Toledo Filho et al 2003) reported their study on development of vegetable fibremortar composites of improved durability. Several approaches were proposed to improve the durability of vegetable fibre-cement composites. These included carbonation of the matrix in a $\mathrm{CO}_{2}$-rich environment; the immersion of fibres in slurried silica fume prior to incorporation in ordinary Portland cement matrix; partial replacement of ordinary Portland cement by undensified silicafume or blast furnace slag. The performance of modified vegetable fibre-mortar composites was analysed in terms of effects of aging in water, exposure to cycles of wetting and drying and open air weathering on the microstructures and flexural behaviour. It was suggested that immersion of natural fibres in a silica fume slurry before the addition to the cement based composites was found to be an effective means of reducing embrittlement of the composite in the environment. Also early cure composites in a $\mathrm{CO}_{2-}$ rich environment and the partial replacement of OPC by undensified silicafume were the efficient approaches in obtaining natural fibres with improved durability.

The capability to absorb energy, called toughness, is important in actual service conditions. For that purpose, an experimental investigation was carried out (Ramakrishna and Sundararajan 2005) on impact strength of a few natural fibre reinforced cement mortar slabs. Four types of natural fibres such as coir, sisal, jute and Hibiscus cannebinus with four different fibre contents such as $0 \cdot 5 \%, 1 \cdot 0 \%, 1.5 \%$ and $2 \cdot 0 \%$ by weight of cement were used. The tests were carried out using repeated projectile test apparatus and the performance of specimens was ascertained based on the parameters viz. impact resistance, residual impact ratio, crack resistance ratio and the condition of fibre at ultimate. From this elaborative test results, it was concluded that coir fibres absorb more energy i.e. $253.5 \mathrm{~J}$ at $2 \%$ fibre content and a fibre length of $40 \mathrm{~mm}$. Microstructure and mechanical properties of waste fibre-cement composites were already studied on 28 days cured specimens (Savastano Jr et al 2005).

At normal 28 days curing ages, some studies have been reported already (Sivaraja and Kandasamy 2007, 2008, 2009). Mechanical strength properties of companion specimens, flexural properties of beams under static and cyclic loading conditions and behaviour of beam-column joints under cyclic loading have been carried out and proved that rural fibres including coir and sugarcane natural fibres exhibit better performance than conventional concrete.

Hence the past research activities on natural fibrous concrete focussed on mechanical strength and microstructural studies at 28 days curing period only. But no elaborative studies have been carried out so far on accelerated curing methods. So this paper focuses on this for getting a rough idea about the life of natural fibres in concrete.

\section{Experimental}

\subsection{Mix and specimens casting}

In preparation of test specimens, 43 grade ordinary Portland cement, natural river sand and stone aggregate were used. The maximum size of coarse aggregate was $19 \mathrm{~mm}$. A sieve analysis conforming to IS 383-1970 was done. The concrete mix was designed to achieve 28 days cube strength of $20 \mathrm{MPa}$ with a constant water cement ratio of $0 \cdot 5$. To avoid the balling effect on concrete during mixing volume fraction of fibres was restricted to $1 \cdot 0 \%$ only. From the earlier studies, it was evident that the optimum volume fraction of fibres in concrete without water reducing admixture was $1 \cdot 5 \%$. Similarly the maximum aspect ratio was 100 . The reason for this limitation was workability of concrete. Probability of heterogeneous distribution and flocculation of fibres in concrete mix was increased by increasing $1 / d$ ratios. Homogeneous distribution of fibres at mixing and placing was required regardless of the type of fibres. According to their shape and quantity, fibres bear some stress that occurs in cement matrix themselves and transfer the other portion of stress at stable cement matrix portions (Yazici et al 2007). Earlier studies (Sivaraja and Kandasamy 2007, 2008, 2009) reported the workability, mechanical and flexural properties of fibrous concrete with the same natural fibres. The optimum volume fraction and aspect ratio obtained from the earlier studies are $1.5 \%$ and 60 . Hence, in the present investigation, the fibrous concrete mix with coir and sugarcane fibres at a volume fraction of $1.5 \%$ and aspect ratio of 60 were selected. Cube specimens of $150 \mathrm{~mm}$ size for compressive strength, cylinder specimens of $150 \mathrm{~mm}$ diameter $\times 300 \mathrm{~mm}$ height and prisms of size, $500 \times 100 \times$ $100 \mathrm{~mm}$ were cast to study the mechanical strength properties.

The test programme also consisted of fabricating reinforced concrete beams of length, $2 \mathrm{~m}$, having identical cross-section of $100 \times 150 \mathrm{~mm}$. The cross-section of beam specimen is

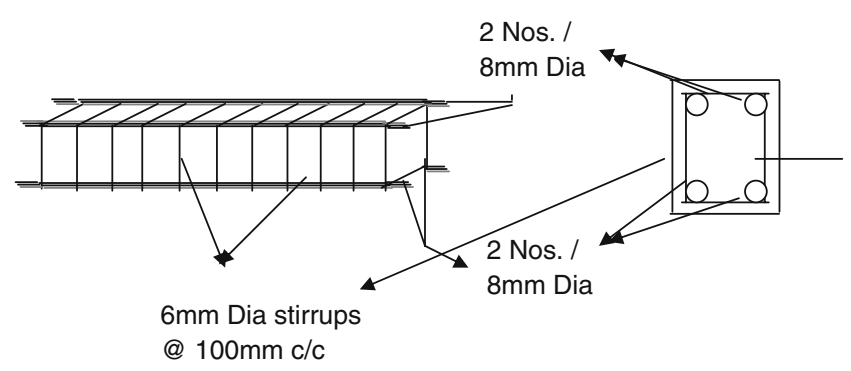

Figure 1. Reinforcement detailing of beam specimen. 
shown in figure 1. To avoid balling effect of fibres, first aggregates and cement were put and allowed to get mixed for $1 \mathrm{~min}$ and water was added within $2 \mathrm{~min}$. Then fibres were uniformly dispersed throughout the mass with slow increment. Now concrete was allowed to mix for $3 \mathrm{~min}$. All the specimens were well compacted using table vibrator. The specimens were demold after 1 day and then placed in a curing tank with $90 \%$ relative humidity and $23^{\circ} \mathrm{C}$ for 28 days of curing. For $12 \mathrm{~h}$ prior to the testing, the specimens were allowed to air dry in the laboratory.

\subsection{Accelerated curing}

Since it was planned to study the behaviour of all the mixes at 28 days, 3, 6, 9, 12, 15, 18, 21 and 24 months intervals, totally 27 specimens each for every test were cast. The water-cement ratio used was $0 \cdot 5$. The fibre content was restricted to $1.5 \%$ volume fraction of concrete volume. Similarly aspect ratio of 60 was considered for both the fibres. The fibre reinforced concrete specimens were allowed for initial curing of 28 days. After 28 days curing, the alternate wetting and drying process was started. The wetting was given by immersing the concrete specimens for 3 days under water. After the wetting process, the specimens were allowed to dry in open air for the remaining 4 days of a week. The specimens were subjected to this alternate wetting and drying process for two years continuously.

\subsection{Test set up for flexural test}

Mechanical strength tests were carried out at room temperature and as per the Indian standards. The mechanical strength tests were carried out in a PC controlled compression testing machine. Modulus of rupture test was conducted in flexural testing machine. Middle third flexural loading

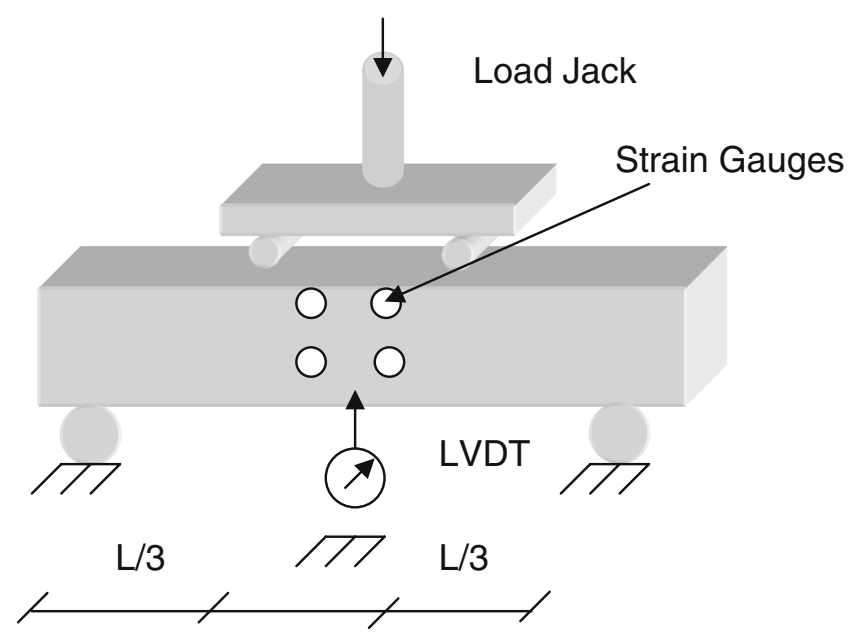

Figure 2. Experimental set up.

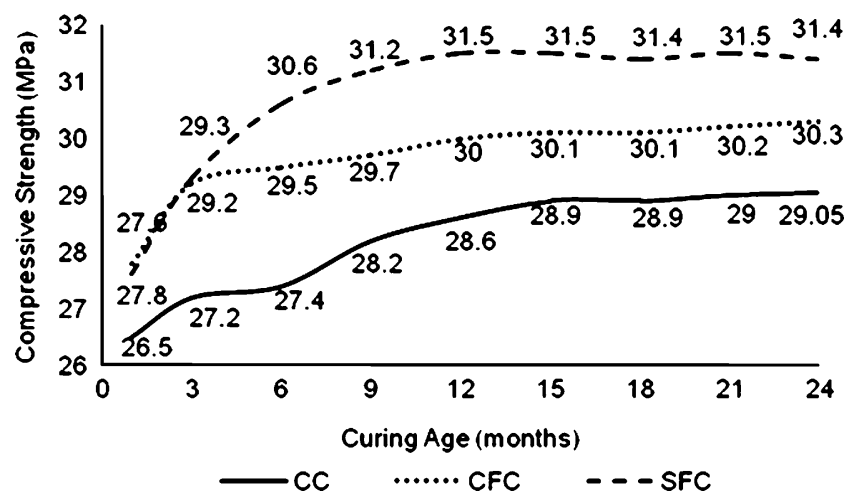

Figure 3. Compressive strength vs curing age.

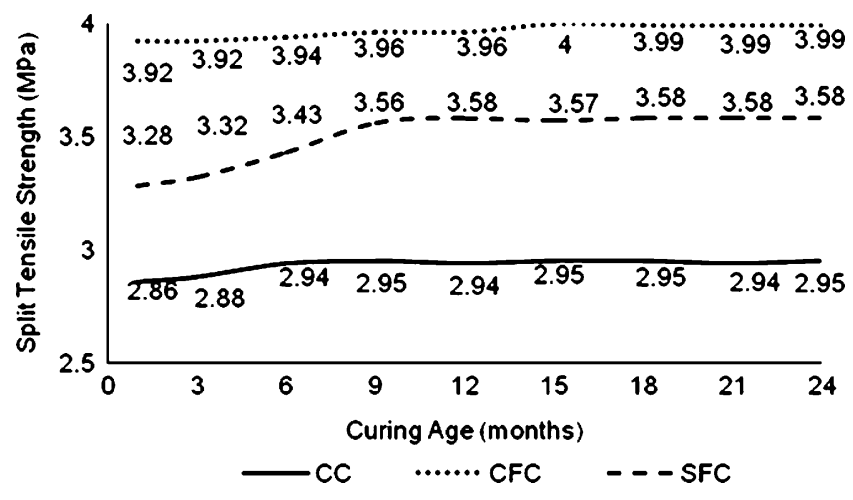

Figure 4. Split tensile strength vs curing age.

was applied on reinforced concrete beams through hydraulic jack. The specimens were placed in $100 \mathrm{~T}$ loading frame and LVDTS was attached to measure the deflection readings. DEMEC as well as electrical strain gauges with strain indicator were used to measure the strain readings both in steel reinforcement and concrete.

To examine and compare the effect on microstructure of natural fibres which are allowed to react with concrete for two years under alternate wetting and drying conditions, two types of samples were taken. One type of samples is the natural fibres used in this study such as coir and sugarcane in the as received condition. The second type of samples was obtained from the fibre reinforced concrete cube specimens. After two years, the fibres from the concrete specimens were collected carefully by using cutters.

\subsection{Instrumentation for microstructural studies}

One of the ways to study the microstructure of fibre specimens is scanned electron microscope (SEM). The instrument used for the present study is SCANNED ELECTRON MICROSCOPE LEO 440, CARL ZEISS, Germany make. It was operated at $20 \mathrm{kV}$. The fibre specimens were gold sputtered and subjected to SEM session. On an OXFORD UK make 


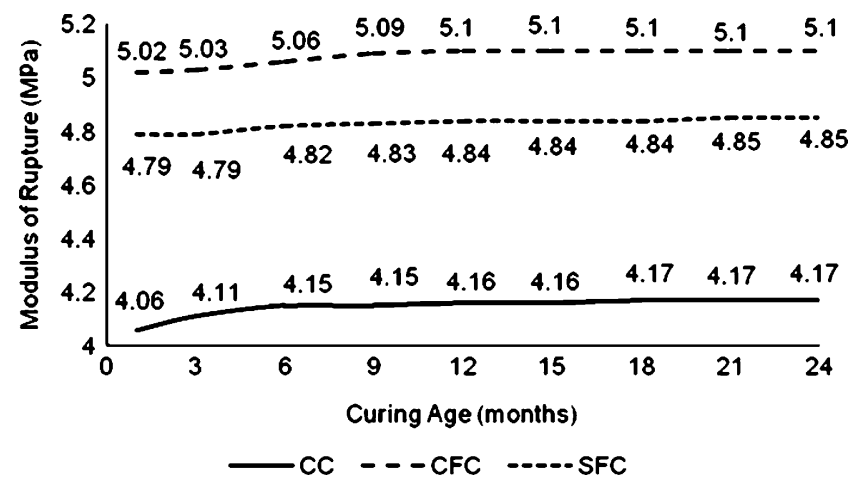

Figure 5. Modulus of rupture vs curing age.

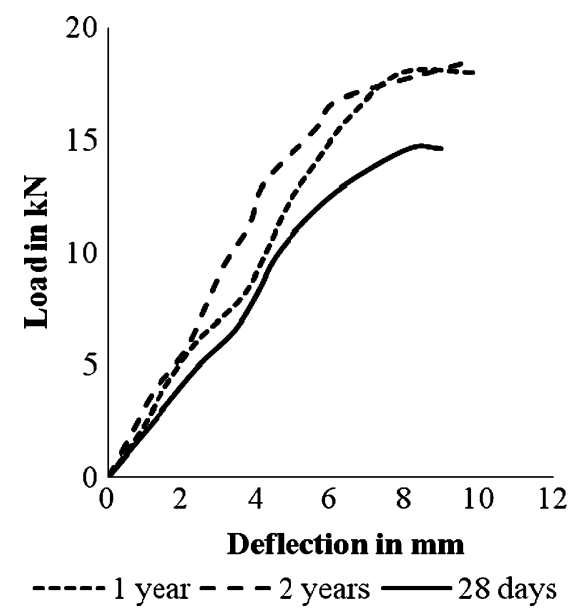

Figure 6. Flexural test curve for conventional concrete beam at different ages.

EDX instrument which was operated at $20 \mathrm{kV}$, the EDX was conducted on the same specimens in an effort to obtain semiquantitative compositional information. The preparation of specimens for EDS started with a high vaccum impregnation using an epoxy binder Araldite diluted in ethanol. The polymerization was completed at $40^{\circ} \mathrm{C}$. Surface lapping was carried out with silica abrasive paper $(13 \mu \mathrm{m})$. Polishing operation was done on $1 \mu \mathrm{m}$ diamond polishing for $10 \mathrm{~min}$. Every surface lapping and polishing was intercalated using acetone cleaning. Finally the specimens were coated with gold before microscopy study.

\subsection{Test methods for durability studies}

The durability of cement concrete is defined as its ability to resist weathering action, chemical attack, abrasion, or any other process of deterioration. Durable concrete will retain its original form, quality, and serviceability when exposed to its environment.

2.5a Sulphate attack: Sulphate attack is the term used to describe a series of chemical reactions between sulphate ions and the components of hardened concrete, principally

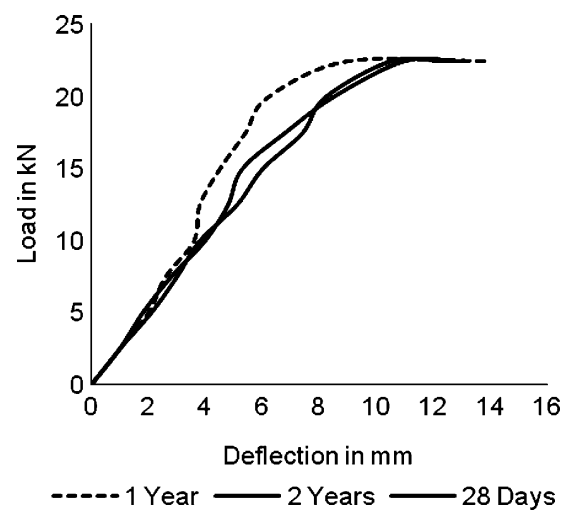

Figure 7. Flexural test curve for CFRC at different ages.

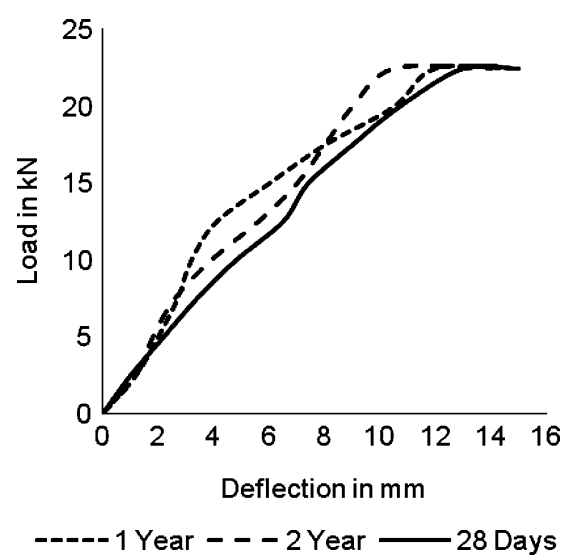

Figure 8. Flexural test curve for SCFRC at different ages.

cement paste, caused by exposure of concrete to sulphate and moisture (Al-Tamimi and Sonebi 2003; Dakshina Murthy et al 2007; Murthi and Sivakumar 2008). Cube specimens of $150 \mathrm{~mm}$ size were cast for conventional, coir $1 \cdot 5 \%$ and sugarcane $1.5 \%$ and cured for 28 days. All concrete specimens were immersed in sulphate solutions for 2 years. The specimens were positioned so that all sides were in contact with the solutions. A non-porous container was selected and sulphate solution was prepared by adding $3 \%$ of concentrated sulphuric acid to 501 of distilled water. The solutions selected for immersion of concrete cylinders was $5 \% \mathrm{H}_{2} \mathrm{SO}_{4}$. The $\mathrm{pH}$ of the solution was regularly monitored and adjusted to keep them constant. The performance of concrete was made based on the assessment of mass loss and strength deterioration factors. Strength deterioration factor is defined as the ratio of change in compressive strength to initial compressive strength.

2.5b Freezing and thawing: Freeze-thaw cycling is one of the main causes of degradation of concrete in cold regions. The degradation stems from the freezing of water in concrete upon cooling, and thawing upon subsequent heating (Marzouk and Jiang 1994; Rutherford et al 1994). The phase transition is accompanied by dimensional change 


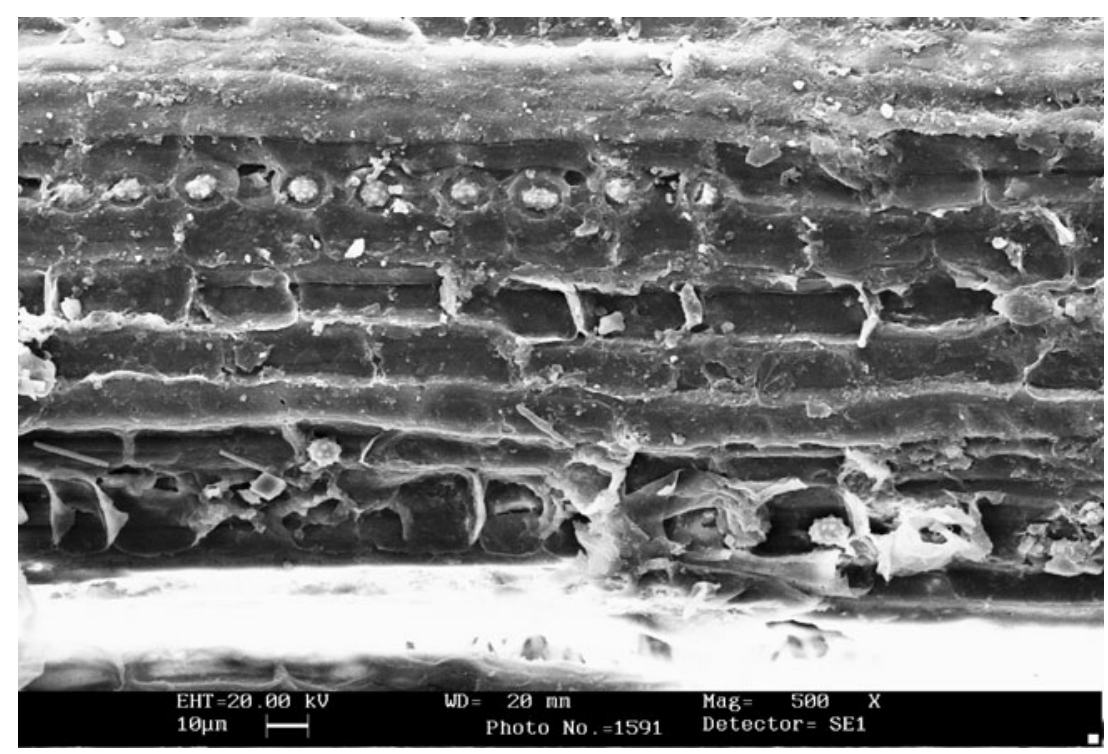

Figure 9. SEM of fresh coir fibre with 1000 magnification.

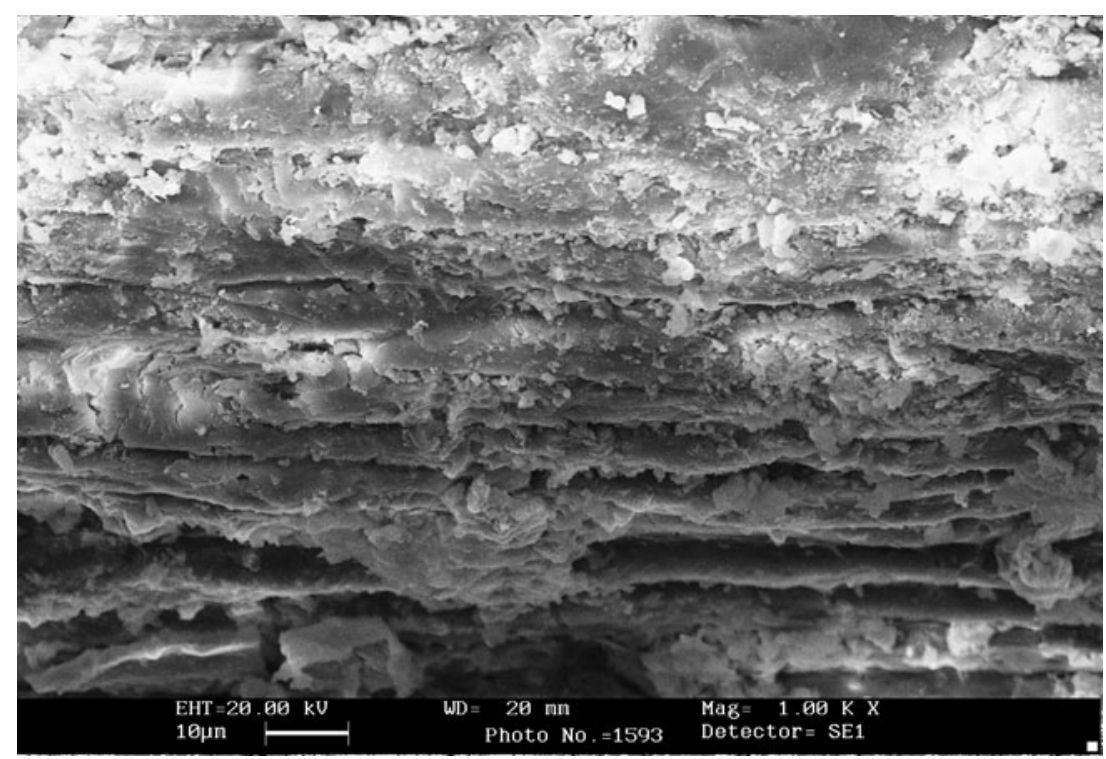

Figure 10. SEM of reacted coir fibre with 1000 magnification.

and internal stress change. Freeze-thaw cycling can result in failure. The freezing and thawing cycling was given according to ASTM C 666 Procedure A (freezing and thawing in water). The temperature maintained was $0^{\circ} \mathrm{F}$ to $40^{\circ} \mathrm{F}$ and $40^{\circ} \mathrm{F}$ to $0^{\circ} \mathrm{F}$ for $4 \mathrm{~h}$. Heating was done in the oven and the cooling was done in the freezer. Cylindrical specimens of $150 \mathrm{~mm}$ diameter and $300 \mathrm{~mm}$ height for conventional, coir $1.5 \%$ and sugarcane $1.5 \%$ mixes were cast and cured for 28 days. The cured specimens were allowed for accelerated curing for 2 years. Then specimens were allowed for 300 numbers of freezing and thawing cycles. At the end of every 30 freezing and thawing cycles, the specimens were tested to obtain mass loss (\%) and relative modulus of elasticity $(\%)$. Due to the experimental facility limitation, static modulus of elasticity (as per compressometer method) was found and used instead of dynamic modulus of elasticity (according to ASTM C-666 2008).

\section{Results and discussion}

Workability of all the three types of concrete mixes was measured using slump cone test. Slump measured for conventional, coir fibre reinforced and sugarcane fibre reinforced concrete was $110 \mathrm{~mm}, 84 \mathrm{~mm}$ and $78 \mathrm{~mm}$, respectively. Both mechanical and microstructural studies of coir and sugarcane fibrous concrete specimens were carried out and the results are discussed here (figure 2). 


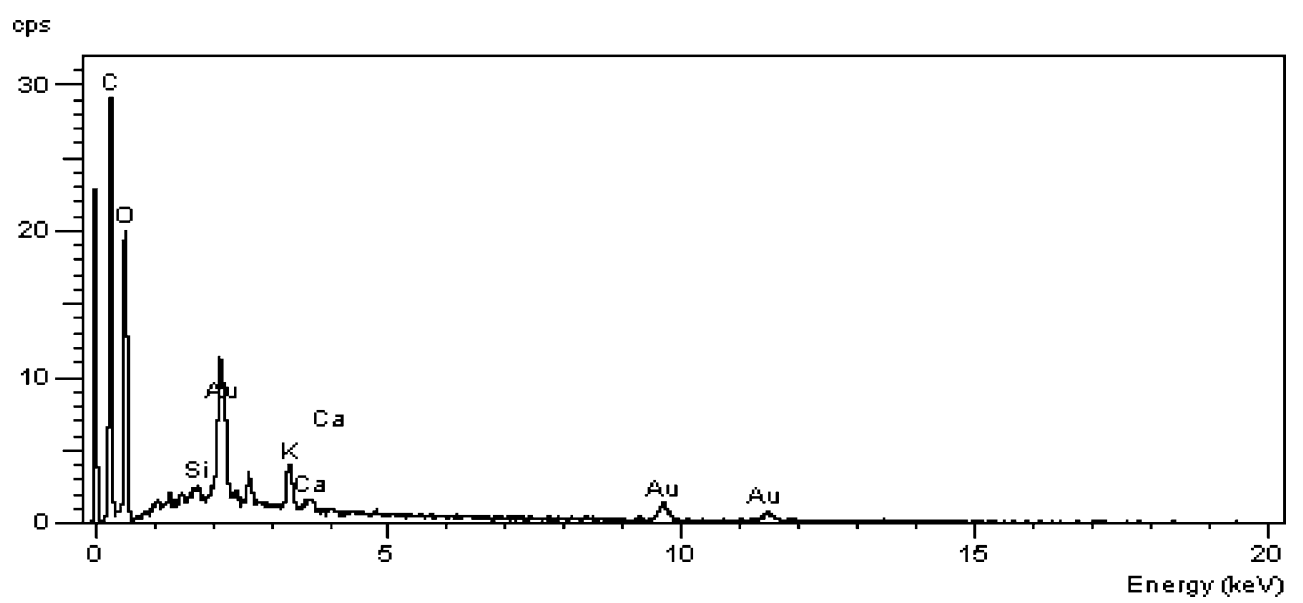

Figure 11. EDAC of fresh coir fibre with 1000 magnification.

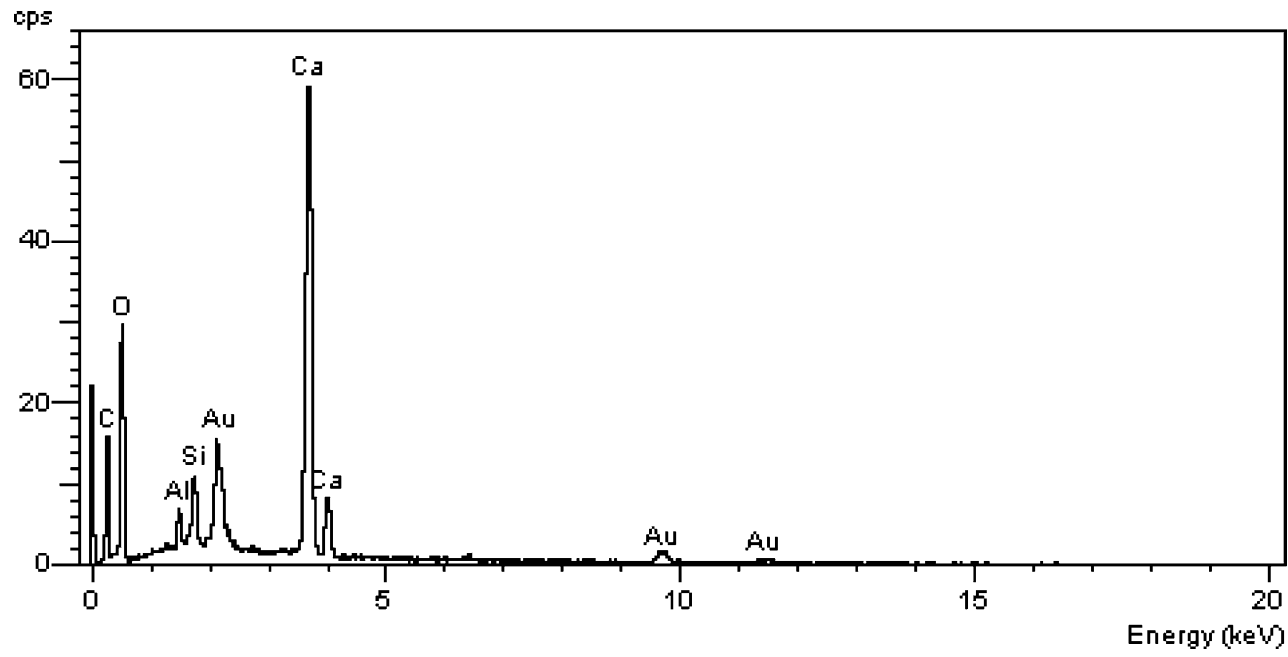

Figure 12. EDAC of reacted coir fibre with 1000 magnification.

\subsection{Mechanical strength properties}

3.1a Compressive strength: Figure 3 shows the variation of compressive strength of conventional, coir fibrous concrete and sugarcane fibrous concrete against age of curing. From the figure it is observed that, all the three mixes exhibit increase in strength over the curing age period. Among all the mixes, coir fibrous concrete mix possesses the highest strength at all the ages. The conventional concrete specimen shows a compressive strength of $26.5 \mathrm{MPa}$ at 28 days curing. The coir and sugarcane fibrous concrete specimens show their compressive strength as 27.8 and $27.6 \mathrm{MPa}$, respectively.

After 6 months of accelerated curing, the conventional concrete exhibits an increment of $3 \cdot 4 \%$ over 28 days of curing specimen. While considering the coir and sugarcane fibrous concrete specimens, they possess increment of $10 \%$ and $11 \cdot 3 \%$ over 28 days strength. At one year age, the conventional specimen shows $8 \%$ and $4.4 \%$ increase in its value over 28 days and 6 months curing age, respectively. At the age of one year, conventional, coir fibrous and sugarcane fibrous concrete specimens exhibit their strength increment as $8 \%, 13 \%$ and $8.7 \%$ over 28 days strength and $4 \cdot 4 \%, 3 \%$ and $1.7 \%$ over 6 months strength.

After one year, up to 2 years of curing age, the compressive strength values of all the three mixes showed not much difference in strength enhancement. So, if 2 years curing age is considered, conventional, coir and sugarcane fibrous specimens give the strength enhancement of $9 \cdot 6 \%, 12 \cdot 94 \%$ and $9 \cdot 78 \%$ over 28 days strength and $1.6 \%, 0 \%$ and $1 \%$ over 1 year age strength. Hence from these results it is observed, though fibrous specimens possess higher strength than conventional concrete at all the ages, after one year curing, the rate of increase in strength is almost nil in fibrous specimens whereas conventional concrete specimen showed slight improvement.

3.1b Split tensile strength: Split tensile strength which is a indirect measure of tensile strength of concrete, of conventional, coir fibrous and sugarcane fibrous concrete specimens against curing age is given in figure 4. From the figure, it is clearly observed that, there is no much 


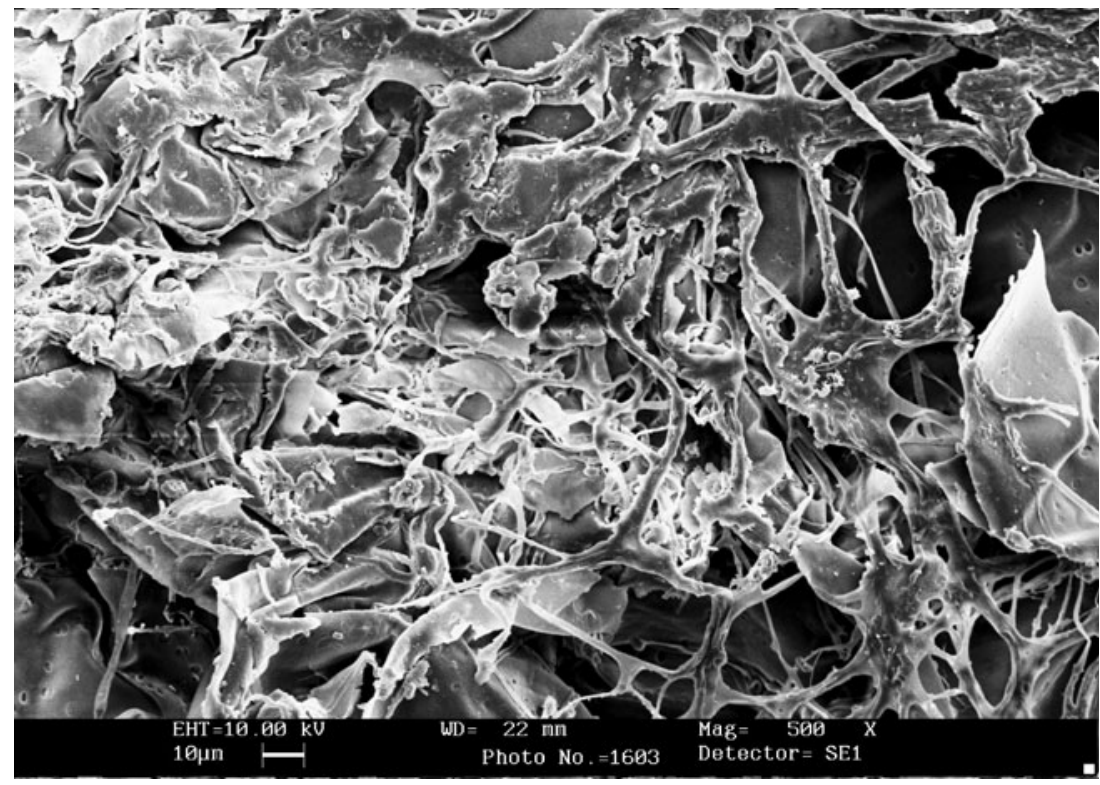

Figure 13. SEM of fresh sugarcane fibre with 500 magnification.

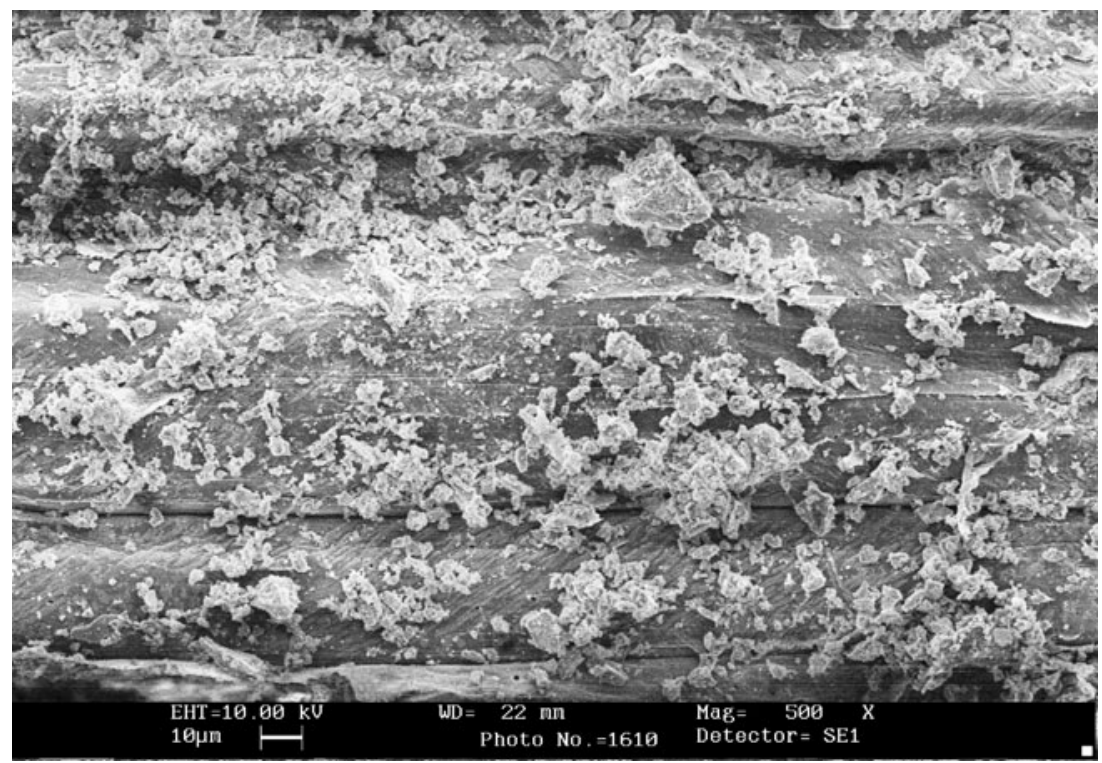

Figure 14. SEM of reacted sugarcane fibre with 500 magnification.

variation in enhancement of tensile strength over a period of two years in all the specimens. Among all, here also the coir fibrous specimen possesses the highest tensile strength. The tensile strength of conventional concrete is $2.86 \mathrm{MPa}$ at 28 days of curing age. Coir and sugarcane fibrous concrete specimens give the 28 days tensile strength as $3.28 \mathrm{MPa}$ and $3.92 \mathrm{MPa}$, respectively. At the end of 2 years, conventional concrete exhibits an increase in tensile strength of $3 \cdot 15 \%$ only. Similarly coir fibrous concrete specimen shows a tensile strength enhancement of $1 \cdot 78 \%$ only. But sugarcane fibrous concrete specimen gives an increment of $9 \cdot 14 \%$. From these results, it is observed that, curing age after 28 days does not make major change in the tensile strength of specimens. And though sugarcane fibrous specimen exhibits little bit lower tensile strength than coir fibrous specimen, the rate of increase in strength is higher than both conventional and coir fibrous specimens.

3.1c Modulus of rupture: Figure 5 shows the relation between modulus of rupture and the curing age of concrete specimens. Conventional concrete gives the modulus of rupture of $4.06 \mathrm{MPa}$ at 28 days of curing. Coir and sugarcane specimens exhibit modulus of rupture as 5.02 $\mathrm{MPa}$ and 4.79 $\mathrm{MPa}$, respectively. From the curves in figure 5 , it is observed that there is no big difference in the strength enhancement between 28 days and 2 years of curing ages. The conventional concrete possesses an 


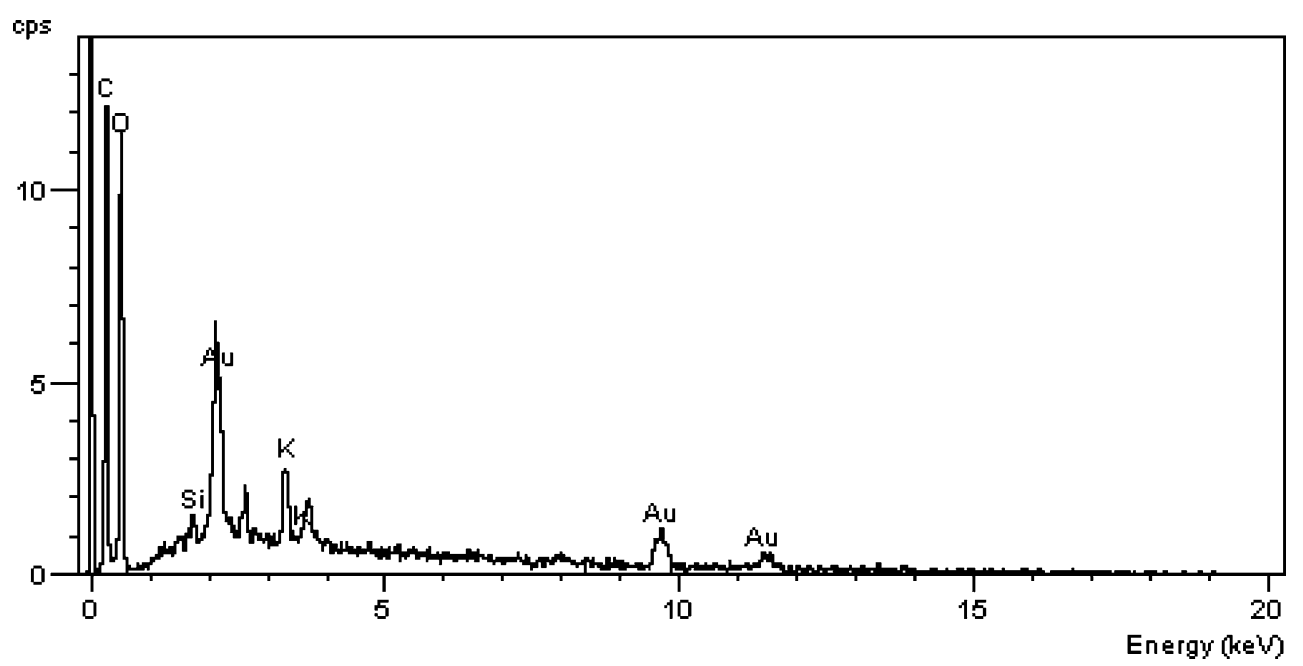

Figure 15. EDAC of fresh sugarcane fibre with 500 magnification.

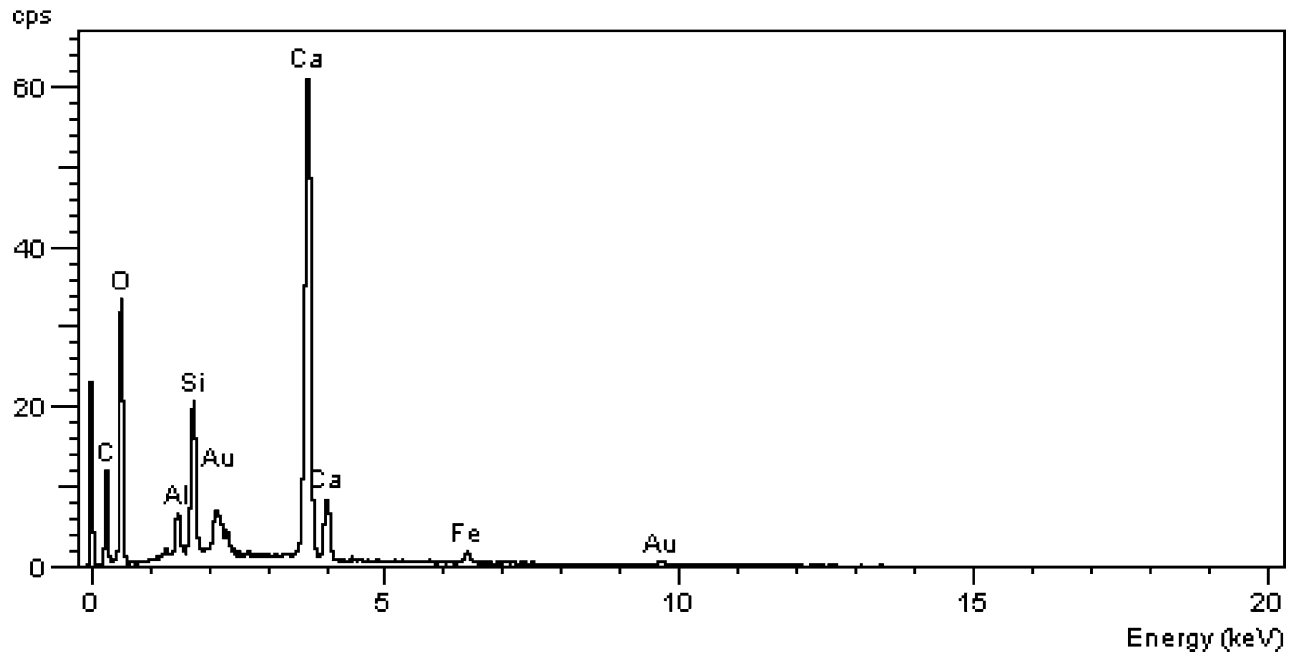

Figure 16. EDAC of reacted sugarcane fibre with 500 magnification.

increment of $2 \cdot 4 \%$ at one year curing age and no further improvement up to the second year. Similarly coir and sugarcane fibrous specimens exhibit the strength enhancement of $1.6 \%$ and $1 \%$, respectively at the age of one year. Here also no improvement in modulus of rupture has been attained after one year of curing age. Hence, it is observed that all the concrete specimens have achieved their maximum strength at one year itself. After one year, the same strength is continued till second year.

3.1d Flexural performance: Load-deflection curves obtained from three point flexural bending test of conventional, coir and sugarcane fibre reinforced concrete beams are shown in figures 6, 7 and 8. From the figures, it is observed that coir fibre reinforced concrete beam behaved almost similarly at the three curing ages such as 28 days, 1 year and 2 years. First cracking load of all the three specimens obtained are same as $4.8 \mathrm{kN}$ and the corresponding deflection is around $2 \mathrm{~mm}$. But while considering the yielding point of the three specimens, coir fibre reinforced concrete specimen at 1 year curing gives the highest value than others. But during the ultimate stage, all the three specimens possess the same performance. Similarly it is known that sugarcane fibre reinforced concrete beam specimen possesses not much difference in flexural behaviour. Hence from these results, it is observed that flexural performance of both the fibrous concrete specimens at the three curing ages such as 28 days, 1 year and 2 years does not possess much difference.

\subsection{Microstructural studies}

Selective natural waste materials at large are utilized to improve the strength and ductility properties of concrete. In this present investigation, concrete composites containing coir fibre and sugarcane fibre are subjected to both SEM and EDX studies. Interesting feature of the microstructure analysis reveals that fineness with fibres is extended longitudinally across all composites. Improvement of the 


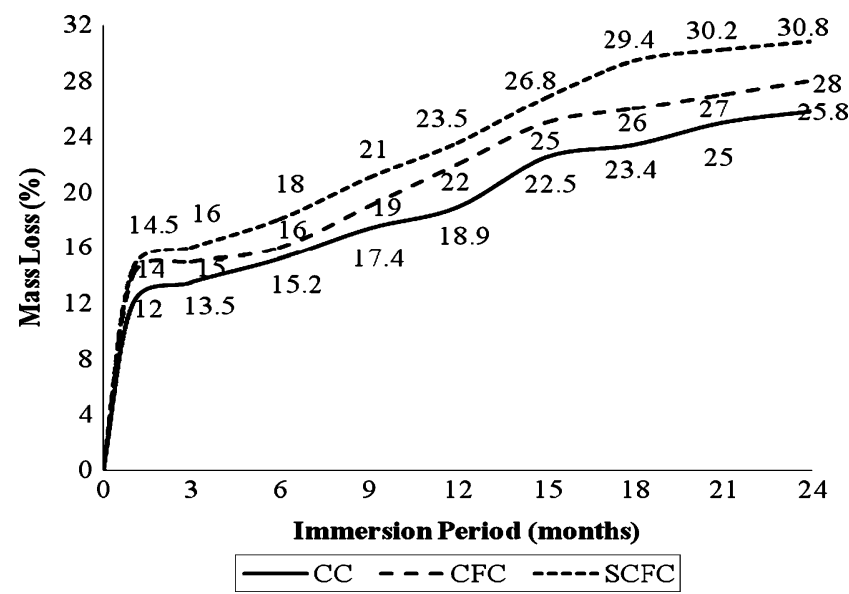

Figure 17. Mass loss due to sulphate attack vs immersion period.

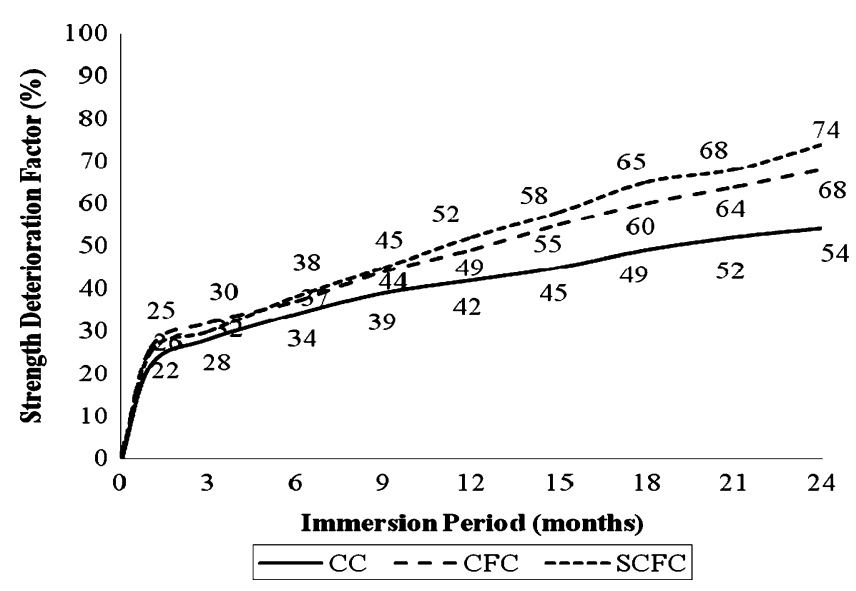

Figure 18. SDF due to sulphate attack vs immersion period.

fibre matrix bond, beyond an acceptable composition leads to detachment of fibres.

3.2a Coir fibres: On examining the coir fibre, fresh sample of small and larger rectangular voids or pores is visible with defined boundaries. The possible binding size between the concrete mass and the fibre is improved by the presence of larger pores. Thus, it is well understood that as shown in figures 9 and 10 , the transition zone exists with concrete and fibre. High porosity is the result of higher rate of initial water absorption. The rapid absorption of water is one among the reasons for higher healing rate exhibited by the fibres. From the EDX spectra recorded which is shown in figures 11 and 12, calcium is the main mineral component, but silicon, aluminium and even potassium is well augmented. A representative EDX spectrum showed the decrease in carbon content in the case of fresh coir fibre. But in the coir fibre reacted with concrete mix, the calcium content has been increased up to $24 \cdot 27 \%$. Also marginal increase of silica, aluminium etc as predicted with a composition of calcium silicate exhibiting the sulphate component to bind with the fibre. On observing the

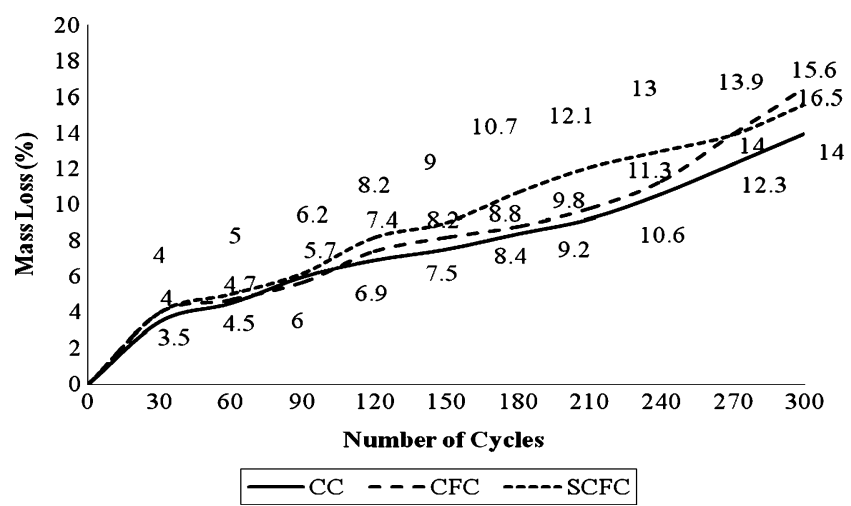

Figure 19. Mass loss due to freezing and thawing vs number of cycles.

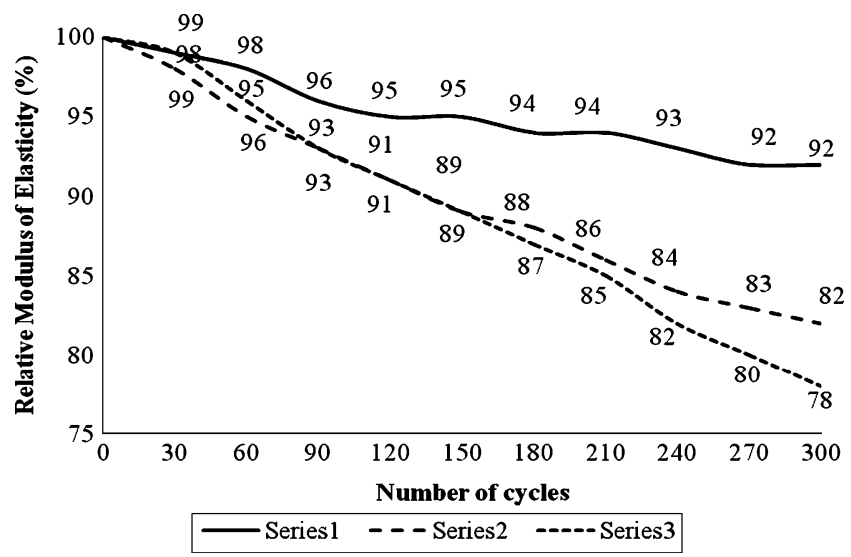

Figure 20. Relative modulus of elasticity vs number of cycles.

microstructure of the coir matrix, it is also observed that the white spots about the fibres are calcium hydroxide as evidenced by its amorphous nature.

3.2b Sugarcane fibres: The SEM of the sugarcane fresh sample exhibits large hairy strands of the fibres with smaller pores as shown in figure 13. The crystalline phases of the concrete mix and sugarcane are attributed to mostly calcium silicate composition. The strands and the mix have resulted in good adhesion. An irregular surface (longitudinal strands) is exhibited. The complete bond formed between the sugarcane and concrete is well characterized by the development of fibre covering of the crystalline phases as shown in figure 14. The EDX analysis of sugarcane as received and reacted with concrete as shown in figures 15 and 16 exhibits increased levels of calcium, silicon and aluminium. Hence a possible phase of ettringite calcium sulphoaluminate $\left(\mathrm{C}_{3} \mathrm{~A} \cdot 3 \mathrm{CaSO}_{4} \cdot 32 \mathrm{H}_{2} \mathrm{O}\right)$ is available due to the hydration and shrinkage process. The reason for strength being constant might be due to natural carbonation of the ettringite phase only upon its existence since innumerous pores has been seen under the 
SEM which probably disintegrates under severe carbonation processes.

$$
\begin{aligned}
& \mathrm{C}_{3} \mathrm{~A} \cdot 3 \mathrm{CaSO}_{4} \cdot 32 \mathrm{H}_{2} \mathrm{O}+3 \mathrm{CO}_{2}, 3 \mathrm{CaCO}_{3}+2 \mathrm{Al}(\mathrm{OH})_{3} \\
& +3 \mathrm{CaSO}_{4} \cdot 2 \mathrm{H}_{2} \mathrm{O}+23 \mathrm{H}_{2} \mathrm{O} .
\end{aligned}
$$

\subsection{Durability properties}

3.3a Sulphate attack: Figures 17 and 18 show the results of resistance against sulphate attack of conventional, coir fibre reinforced and sugarcane fibre reinforced concrete specimens. Average values of three specimens are given in the figures. The obtained mass loss in conventional concrete at 30 days of immersion was $12 \%$. This value was increased as $18.9 \%$ and $25 \cdot 8 \%$ at one year and two years of immersion periods. While coir reinforced concrete was considered, the mass loss was $14 \%, 22 \%$ and $28 \%$ for 30 days, one year and two year immersion periods, respectively. The higher mass loss was obtained in sugarcane bagasse reinforced concrete specimens such as $14.5 \%, 23.5 \%$ and $30.8 \%$ for 30 days, one year and two years of immersion periods, respectively. Compression strength deterioration factor for conventional, coir fibre reinforced, sugarcane fibre reinforced concrete cube specimens also showed similar pattern of degradation. Strength deterioration of conventional concrete was obtained as $22 \%, 42 \%$ and $54 \%$ at the immersion period of 30 days, one year and two years, respectively. Coir fibre reinforced concrete possessed $24 \%, 49 \%$ and $68 \%$ deterioration in compressive strength at immersion periods of 30 days, one year and two years, respectively. Similarly, highest deterioration was obtained in sugarcane fibre reinforced concrete as $25 \%, 52 \%$ and $74 \%$, respectively for 30 days, one year and two years of immersion periods. From the figures, it is evident that natural fibre reinforced concretes were less attractive than conventional concrete in resisting sulphate attack.

3.3b Freezing and thawing: Cylindrical concrete specimens of conventional, coir fibre reinforced and sugarcane fibre reinforced samples were subjected to freezing and thawing cycles and further tested to find out the mass loss and chord modulus of elasticity. Figure 19 shows the mass loss of three different concrete mixes against number of cycles. From the figure, it was observed that mass loss at the end of 300 cycles of freezing and thawing was $14 \%$ for conventional concrete. This value for coir fibre reinforced and sugarcane fibre reinforced concrete obtained were $16.5 \%$ and $15.6 \%$, respectively. The corresponding relative modulus of elasticity obtained for conventional, coir fibre reinforced and sugarcane fibre reinforced concrete were $92 \%, 82 \%$ and $78 \%$, respectively. From figure 20, it was evident that resistance against freezing and thawing effects was same in the three types of concrete at the initial cycles, but in later stage the resistance was smaller in natural fibre reinforced concrete specimens than conventional concrete specimen.

\section{Conclusions}

From this extensive experimental study, it is well known that natural fibres enhance all the strength and flexural performance of concrete. The effect of curing ages on mechanical properties such as compressive strength, split tensile strength, modulus of rupture and flexural performance and microstructural properties have been ascertained and discussed. The following conclusions are drawn from this investigation:

(I) At all the curing ages, both the natural fibres such as coir and sugarcane fibres enhance all the three mechanical strength properties such as compressive strength, split tensile strength, modulus of rupture and flexural performance.

(II) Though the natural fibres enhance the strength properties at earlier curing ages, the rate of increments are lower than conventional concrete specimen at later curing ages.

(III) The flexural performance of the natural fibre reinforced concrete beam specimens do not yield much difference at the three curing ages such as 28 days, 1 year and 2 years. They possess a little bit difference at the yielding stage only.

(IV) SEM and EDS analyses confirmed that the boundary of fibre-matrix transition zone have excellent adhesion. The impregnation of calcium content on the fibre walls showed better strength enhancement.

(V) Both the natural fibre reinforced concretes were less susceptible against sulphate attack in terms of mass loss and compressive strength deterioration. Since the difference observed was large, application of natural fibre reinforced concrete would be limited in marine areas.

(VI) Although effect of freezing and thawing on natural fibre reinforced concrete was higher than conventional concrete, the difference in mass loss and relative modulus of elasticity between fibre reinforced and conventional concrete was acceptable.

\section{Acknowledgements}

The authors gratefully acknowledge the financial support extended by the Coir Board (Ministry of Agro and Industries, Govt. of India) to carry out this research project. Also they acknowledge the National Aerospace Laboratories, Bangalore, for providing SEM analysis.

\section{References}

Al-Oraimi S K and Seibi A C 1995 Compos. Struct. 32165

Aziz M A, Paramasivam P and Lee S L 1984 Concrete reinforced with natural fibres-New reinforced concretes (ed) R N Swamy (Surrey: Surrey University Press) pp 106-140 
Al-Tamimi A K and Sonebi M 2003 J. Mater. Civil Engg. 4 354

ASTM C666 / C666M-03 2008 Standard test method for resistance of concrete to rapid freezing and thawing (West Conshohocken, PA: ASTM International)

Bilba K, Arsene M A and Ouensanga A 2003 Cem. Concr Compos. 2591

Dakshina Murthy N R, Raaseshu D and Seshagiri Rao M V 2007 Asian J. Civil Engg. (Building and Housing) 203

Marzouk H and Jiang D 1994 ACI Mater. J. 91577

Murthi P and Sivakumar V 2008 Asian J. Civil Engg. (Building and Housing) 9473

Ramakrishna G and Sundararajan T 2002 J. Ferrocement 32 49, 139
Ramakrishna G and Sundararajan T 2005 Cem. Concr. Compos. 27 547

Rutherford J H, Langan B W and Ward M A 1994 Cem. Concr. Aggreg. 1678

Savastano Jr H, Warden P G and Coutts R S P 2005 Cem. Concr. Compos. 27583

Sivaraja M and Kandasamy S 2007 J. Engg. Appl. Sci. 21620

Sivaraja M and Kandasamy S 2008 Reinf. Plast. Compos. 27135 Sivaraja M and Kandasamy S 2009 Int. J. Mater. Prod. Technol. 136385

Toledo Filho Romildo D, Ghavami Khosrow, England George L and Scrivener Karen 2003 Cem. Concr. Compos. 25185

Yazici Semsi, Inan Gözde and Tabak Volkan 2007 Const. Build. Mater. 211250 